\title{
Use of Current Therapeutic Devices in the Treatment of Restless Legs Syndrome: A review
}

\author{
Rajiv Tonk ${ }^{1}$, Parul Sharma ${ }^{2}$, Shweta Sharma ${ }^{3}$, Vinika Siwach ${ }^{4}$ \\ ${ }^{1}$ Head \& Associate Professor, School of Physiotherapy, Delhi Pharmaceutical Sciences \& Research University, \\ New Delhi, ${ }^{2}$ Ph.D. Student, School of Physiotherapy, Delhi Pharmaceutical Sciences \& Research University, New \\ Delhi, ${ }^{3}$ Assistant Professor, Department of physiotherapy, Manav Rachna International University, Faridabad, \\ ${ }^{4}$ Assistant Professor, Department of physiotherapy, Jagan Nath University, Haryana, Bahadurgarh, Jhajjar Road
}

\begin{abstract}
Introduction: Restless legs syndrome (RLS), a current neurological sensory processing disorder in developing countries, characterized by physical discomfort or painful feelings in the thighs, calves and feet resulting in causing strong urge to move one's legs to alleviate pain. RLS is commonly found in older people and females. RLS is closely associated with iron deficiency, pregnancy and uremia. The pathophysiological pathways are still unknown.
\end{abstract}

Methodology: Related Studies has been taken out from databases, MEDLINE (PubMed), Pedro and the Cochrane Database of Systematic Re-views.

Result and Discussion: The various therapeutic devices are used to treat the Restless legs syndrome (RLS) such as whole body vibration (WBV), pneumatic compression therapy (PCT) and near-infrared light (IR) for enhancement of circulation \& for enhancement of counter stimulation use transcutaneous electrical nerve stimulation (TENS) and the vibration Relaxis pad (VRP).

Conclusion: The Relaxis Pad is more effective as compared to other therapeutic devices to relieve periodic limb movements \& quality of sleep.

Keywords: Restless legs syndrome, Therapeutic Devices, circulation, counter-stimulation.

\section{Introduction}

Karl Ekbom proposed the term RLS, which is also called as Ekbom's syndrome in 1945. Restless legs syndrome or Willis-Ekbom Disease is a common neurological sensory-motor condition characterized by predominantly abnormal night pain \& abnormal sensations relieved by limb movement. Till now, There is

\section{Corresponding Author:}

\section{Mrs. Parul Sharma}

Ph.D. Student, School of Physiotherapy, Delhi

Pharmaceutical Sciences \& Research University

e-mail: drparulsharma.sharma@gmail.com

Ph. No.: 09896379188 lot of difficulties in diagnosing the restless legs syndrome or willis-ekbom disease. There is no any evidence of biomarkers \& no final distinct clinical findings has been found that help in making diagnosing RLS. Broadly, the nature of chief complaints of patient determine the diagnosis \& it can be treated with pharmaceuticals or conservatively. ${ }^{1}$

The purpose of this article to review available conservative treatment through using therapeutic device such as WBV, PCT and IR use enhancement of circulation \& TENS and VRP use counter stimulation.

Epidemiology: The prevalence rate of RLS is estimated as $5 \%$ in the general population. ${ }^{2}$ The prevalence in women is almost twice as often as men and in women, it is increasing with age drastically. ${ }^{3}$ 
Pathophysiology: A lot of research studies understood the three factors for the cause of RLS: brain concentration of iron, brain dopamine concentrations and genes.

Diagnosis: International RLS study group in 1995 published the first approved criteria was following diagnostic criteria are as follows ${ }^{4,5}$

1. Whenever patient may feel uncomfortable or unpleasant sensations in the legs, patient may have urge to move the legs.

2. Whenever patient may feel unpleasant sensations during the periods of rest or slowness in activites such as lying down or sitting, Patient may have a strong desire to move the legs.
3. Patient may get partially or totally relieved by movement such as walking or stretching from unpleasant sensations.

4. Whenever patient feels any unusual \& bad sensations during rest or limited activityor become worse in the evening or night than during the day, patient may have urge to move the legs.

Related Conditions and Exposures: Sometimes RLS is related with general medical conditions referred to as secondary RLS such as renal failure, iron deficiency and pregnancy. ${ }^{6,7}$ O'Keffe et al. experimented a study and concluded that Low levels of ferritin (a sensitive indicator of body iron stores) in experimental group (RLS patients group) was more significant than in control group. ${ }^{8}$ Increased prevalence of RLS in pregnancy was firstly noted by Ekbom. ${ }^{9}$

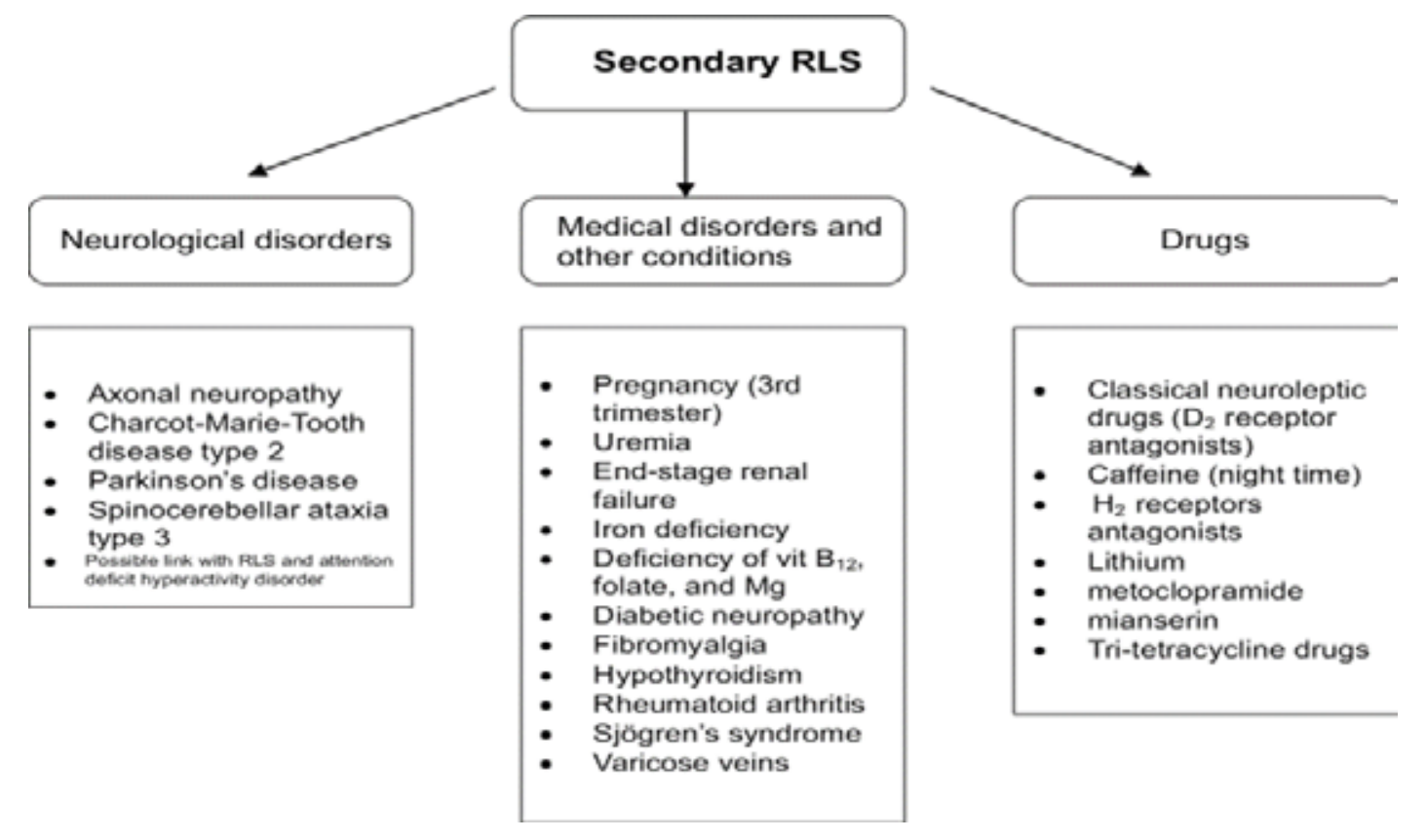

Treatment: Restless legs syndrome can be treated on the basis of chief complaints of patients by Drug related therapy (eg, dopaminergic drugs). ${ }^{10} \&$ Non-drug related treatment. ${ }^{11}$ Nondrug-related treatment options includes therapeutic devices.

Whole body Vibration: RLS/WED patients having an urge to move the extremity (arms or legs) is the result of a feedback mechanism originating in the muscle or other tissue that signals low oxygenation and that the co whole-body vibration (WBV) devices deliver vibration through oscillating plates using two different systems: either reciprocating vertical displacements on the left and right side of a fulcrum, or the whole plate oscillating uniformly up and down. ${ }^{13}$ Investigations using healthy individuals have shown that WBV results in endothelial shear stress ${ }^{14}$ that is sufficient to produce nitric oxide (NO), a powerful vasodilator. It decreases vascular resistance, an increase in skin blood flow \& consequent movement and muscle contractions lead to the desired enhanced oxygen supply. ${ }^{14,15}$ The vibrations are transmitted through the axial and appendicular skeleton and the related potential damage to vision and hearing. ${ }^{16,17}$ No information on patient satisfaction is available. $^{18}$ 
Pneumatic compression devices: $\mathrm{PCT}$ is a therapeutic modality that consists of inflatable cuffs for axilla, arms, hands \& foot to improve the blood circulation for the management of lymphedema and venous insufficiency Intermittently. ${ }^{19}$

It is proposed that the release of endothelial mediators i.e. Nitric oxide, that promotes blood flow to get rid of RLS/WED symptoms by activation of vascular compression \& also improve venous and lymphatic drainage and decreases ischemia. ${ }^{20}$ On the note on safety concern, according to recent studies, Patients continued to have poor outcomes after using pneumatic compression devices. Some patients have experienced pain, discomfort, sweating \& itching in the compression sleeve. $^{21,22}$

Near-infrared light: As we know that the range of wavelength of near infra-red light $(750-1,000 \mathrm{~nm})$ is far greater than visible light $(380-740 \mathrm{~nm})$, therefore it penetrates deeply into the dermal layers of skin than IR and improves circulation. The NIR therapy is based on the principle that itactivates the enzyme Nitric oxide synthase 3 (NOS-3) and it produces Nitric oxide in the endothelium to improve blood circulation. The results shown in the experimental studies by assessing the heating in underlying tissues at deeper layers of skin $(0.5,1 \& 1.5 \mathrm{~cm})$ and found that the increased temperature on the skin surface (approximately $40^{\circ} \mathrm{C}$ ). ${ }^{27}$ Therefore, NIR is efficacious for RLS. ${ }^{28,29}$

TENS: Transcutaneous electrical nerve stimulation (TENS) is the non-invasive electrotherapeutic technique to relieve pain by the application of an electrical current through electrodes placed on the skin. ${ }^{30}$ Low frequency TENS is well-known as acupuncture TENS by activating A-Delta nerve fibres to release the endorphins for relieving pain. ${ }^{31,32}$ TENS treatment is found to be safe \& effective. According to recent case study a treatment of TENS and vibration when applied in combination, it was much more effective. ${ }^{33}$

Vibration (Relaxis) Pad: The various sizes of Relaxis pads are available in variable sizes, controller and power supply and RLS/WED patients receive 35-minute therapy cycle. This pad is exclusively known to improve the sleep quality and quality of life. ${ }^{34,35}$ The Relaxis pad is found to be safe \& effective. This device is strongly contra indicated in deep venous thrombosis to prevent the free-floating of blood clot. ${ }^{36}$ Approximately $10 \%$ of the patients eventually develop skin irritation from VRP. ${ }^{37}$ According to recent Studies concluded that improvement in sleep was remarkably higher in VRP group as compared to sham pad group. ${ }^{38,39,40}$

\section{Conclusion}

The relaxis pad is the most safe \& effective among all these therapeutic devices which are discussed above for the treatment of symptoms of restless legs syndrome. $^{41,42,43}$

\section{Source of Funding: Nil}

\section{Ethical Clearance: Nil}

\section{Conflict of Interest: Nil}

\section{References}

1. Tatlow WFT, Restless legs, CMAJ, 1954;71:191-2

2. Ondo WG, Restless Legs Syndrome. In: Jankovic J, Tolosa E (eds), Parkinson's Disease and Movement Disorders, 5th edition, Philidelphia: Lippincott, Williams and Wilkins, 2007; 409-20

3. David B Sommer, Mark Stacy, epidemiology and pathophysiology of restless legs syndromeus, Neurology, 2007;4(1)

4.. Allen RP, Picchietti D, Hening WA, et al, Restless legs syndrome: diagnostic criteria, special considerations and epidemiology: A report from the restless legs syndrome diagnosis and epidemiology workshop at the National Institutes of Health, Sleep Med, 2003;4:101-19

5. Garcia-Borreguero D, Larrosa O, de la Llave Y, et al., Correlation between rating scales and sleep laboratory measurements in restless legs syndrome, Sleep Med, 2004;5:561-5.

6. Ali M Bozorg, Selim R Benbadis, Medscape, 2017

7. Winkelman JW, Chertow GM, Lazarus JM, Restless legs syndrome in end-stage renal disease, Am J Kidney Dis, 1996;28:372-8

8. O'Keeffe ST, Gavin K, Lavan JN, Iron status and restless legs syndrome in the elderly, Age Ageing, 1994;23:200-203

9. Manconi M, Govoni V, De Vito A, et al., Pregnancy as a risk factor for restless legs syndrome, Sleep Med, 2004;5:305-8

10. Skomro RP, Ludwig S, Salamon E, Kryger MH, Sleep complaints and restless legs syndrome in adult type 2 diabetics, Sleep Med, 2001;2:417-22 
11. Mitchell UH. Nondrug-related aspect of treating Ekbom disease, formerly known as restless legs syndrome. Neuropsychiatr Dis Treat. 2011;7: 251257

12. Coccagna G, Vetrugno R, Lombardi C, Provini F. Restless legs syndrome: an historical note. Sleep Med. 2004;5:279-283

13. Cardinale M, Wakeling J. Whole body vibration exercise: are vibrations good for you? Br J Sports Med. 2005;39(9):585-589; discussion 589

14. Lohman E, Petrofsky J, Maloney-Hinds C, BettsSchwab H, Thorpe D. The effect of whole body vibration on lower extremity skin blood flow in normal subjects. Med Sci Monit. 2007; 13(2): CR71-CR76

15. Games KE, Sefton JM, Wilson AE. Whole-body vibration and blood flow and muscle oxygenation: a meta-analysis. J Athl Train. 2015;50(5): 542-549. and augmented muscle blood volume.19

16. Muir J, Kiel DP, Rubin CT. Safety and severity of accelerations delivered from whole body vibration exercise devices to standing adults. J Sci Med Sport. 2013; 16(6):526-531

17. Caryn RC, Hazell TJ, Dickey JP. Transmission of acceleration from a synchronous vibration exercise platform to the head. Int J Sports Med. 2014;35(4):330-338.

18. Hadi SC, Delparte JJ, Hitzig SL, Craven BC. Subjective experiences of men with and without spinal cord injury: tolerability of the juvent and WAVE whole body vibration plates. PM R. 2012;4(12):954-962

19. Manfredini F, Malagoni AM, Felisatti M, et al. Acute oxygenation changes on ischemic foot of a novel intermittent pneumatic compression device and of an existing sequential device in severe peripheral arterial disease. BMC Cardiovasc Disord. 2014; 14:40

20. Sun D, Huang A, Recchia F, et al. Nitric oxidemediated arteriolar dilation after endothelial deformation. Am J Physiol Heart Circ Physiol. 2001; 280:H714-H721

21. Manfredini F, Malagoni AM, Felisatti M, et al. Acute oxygenation changes on ischemic foot of a novel intermittent pneumatic compression device and of an existing sequential device in severe peripheral arterial disease. BMC Cardiovasc Disord. 2014; 14:40
22. Moore K, Nichols-Willey J, Orlosky-Novack J. Enhancing patient outcomes with sequential compression device therapy. Am Nurse Today. 2013;8(8). Available from: http://www. americannursetoday.com/enhancing-patientoutcomes-with-sequential-compression-devicetherapy/. Accessed August 25, 2015

23. Eliasson A, Lettieri C. Sequential compression devices for treatment of restless legs syndrome. Medicine. 2007;86(6):317-323.

24. Rajaram S, Shanahan J, Ash C, Walters A, Weisfogel G. Enhanced external counter pulsation (EECP) as a novel treatment for restless legs syndrome (RLS): a preliminary test of the vascular neurologic hypothesis for RLS. Sleep Med. 2005;6:101-106

25. Rajaram S, Rudzinskiy P, Walters A. Enhanced external counter pusation (EECP) for restless legs syndrome (RLS): preliminary results in a parallel double-blind study. Sleep Med. 2006;7:390-391

26. Matsunga K, Furchgott R. Interaction of light and sodium nitrite in producing relaxation of rabbit aorta. J Pharmacol Exp Ther. 1989;248(2): 687-695. Buga G, Gold M, Fukuto J, Ignarro L. Shear stress induced release of nitric oxide from endothelial cells grown on beads. Hypertension. 1991; 17:187-193).

27. Mitchell UH, Johnson AW, Myrer JW, Hager RL, Eggett DL. A randomized single-blind controlled trial comparing two monochromatic near-infrared light devices: implications for tissue heating and safety. Am J Phys Med Rehabil. 2012;91(9):789796.

28. Mitchell UH, Myrer JW, Johnson AW, Hilton SC. Restless legs syndrome and near-infrared light: an alternative treatment option. Physiother Theory Pract. 2011;27(5):345-351

29. Guffey JS, Motts S, Barymon D, et al. Using near infrared light to manage symptoms associated with restless leg syndrome. Physiother Theory Pract. 2015.

30. DeSantana JM, Walsh DM, Vance C, Rakel BA, Sluka KA. Effectiveness of transcutaneous electrical nerve stimulation for treatment of hyperalgesia and pain. Curr Rheumatol Rep. 2008; 10(6):492-499

31. DeSantana JM, Walsh DM, Vance C, Rakel BA, SlukaKA. Effectiveness of transcutaneous electrical nerve stimulation for treatment of hyperalgesia and pain. Curr Rheumatol Rep. 2008; 10(6):492-499 
32. Basbaum AI, Fields HL. Endogenous pain control mechanisms: review and hypothesis. Ann Neurol. 1978;4(5):451-462

33. Pallett EJ, Rentowl P, Johnson MI, Watson PJ. Implementation fidelity of self-administered transcutaneous electrical nerve stimulation (TENS) in patients with chronic back pain: an observational study. Clin J Pain. 2014;30(3):224-231

34. Burbank F, Buchfuhrer M, Kopjar B. Sleep improvement for restless legs syndrome patients. Part I: pooled analysis of two prospective, doubleblind, sham-controlled, multi-center randomized clinical studies of the effects of vibrating pads on RLS symptoms. J Parkinsonism Restless Legs Syndrome. 2013;2013(3):1-10

35. Melzack R, Wall PD. Pain mechanisms: a new theory. Science. 1965; 150:971-979

36. Stop your restless legs symptoms; 2015. Available from: http://myrelaxis.com/us/. Accessed August 27, 2015

37. Burbank F, Buchfuhrer M, Kopjar B. Improving sleep for patients with restless legs syndrome. Part II: meta-analysis of vibration therapy and drugs approved by the FDA for treatment of restless legs syndrome. J Parkinsonism Restless Legs Syndrome. 2013;3:11-22
38. DeSantana JM, Walsh DM, Vance C, Rakel BA, Sluka KA. Effectiveness of transcutaneous electrical nerve stimulation for treatment of hyperalgesia and pain. Curr Rheumatol Rep. 2008; 10(6):492-499

39. Basbaum AI, Fields HL. Endogenous pain control mechanisms: review and hypothesis. Ann Neurol. 1978;4(5):451-462

40. Guieu R, Tardy-Gervet MF, Blin O, Pouget J. Pain relief achieved by transcutaneous electrical nerve stimulation and/or vibratory stimulation in a case of painful legs and moving toes. Pain. 1990;42(1):43-48.

41. Kushida C, Allen R, Atkinson M. Modeling the causal relationship between symptoms associated with restless legs syndrome and the patient-reported impact of RLS. Sleep Med. 2004;5:485-488

42. Allen RP, Kosinski M, Hill-Zabala CE, Calloway MO. Psychometric evaluation and tests of validity of the Medical Outcomes Study 12-item Sleep Scale (MOS sleep). Sleep Med. 2009; 10(5):531539

43. Burbank F, Buchfuhrer M, Kopjar B. Sleep improvement for restless legs syndrome patients. Part I: pooled analysis of two prospective, doubleblind, sham-controlled, multi-center randomized clinical studies of the effects of vibrating pads on RLS symptoms. J Parkinsonism Restless Legs Syndrome. 2013;2013(3):1-10 